\title{
The technique of X-ray diffraction for stresses quantification in metallic elements
}

\author{
S. Sánchez-Beitia \& J. Barrallo \\ Faculty of Architecture, Basque Country University, Spain
}

\begin{abstract}
X-ray diffraction technique for residual stresses quantification in metallic parts has been widely applied for decades in many industrial sectors. This paper describes the calibration at a laboratory of this technique in order to adapt it for the quantification of the mechanical stresses in metallic structures. A small structure specifically built for this research has been repeatedly loaded at the laboratory. In each load level the stresses in a bar of the structure have been quantified by means of X-ray diffraction technique. Correlation between the stresses deducted experimentally and the applied stresses is excellent. As a conclusion it can be stated that the X-ray diffraction technique can be used for stress analysis in metallic elements. The technique is absolutely non destructive and appropriate to be used in Heritage Constructions.
\end{abstract}

Keywords: structural stresses, residual stresses, X-ray diffraction technique, metallic structures.

\section{Introduction}

One of the most interesting challenges of the scientific community in the structural analysis field is the development of new non destructive experimental techniques (NDT). The research here presented deals with the applicability of the $\mathrm{X}$-ray diffraction technique for stresses quantification in metallic structures. The main problem in all cases for in-situ stresses measurements is that they have already been applied. Considering that it is not possible to apply any load (or unload) to a real structure, a parameter needs to be selected that can be determined experimentally. The experimental value of this parameter should lead to the deduction of the stress states. In this case the appropriate parameter is the separation " $d$ " of the crystallographic planes of the steel phases (ferrite, 
pearlite,...). In other words, the "strain gage" employee is the family of crystallographic planes that contribute to the diffraction phenomenon.

X-ray diffraction technique is widely applied for residual stresses measurements in metallic materials [1-5]. Since 2008 [6] authors attempt to introduce the X-ray diffraction technique in different applications for the construction sector (buildings and civil engineering structures). Potential applications for heritage constructions are evident. Furthermore, many ancient constructions in masonry contain recent metallic elements acting as reinforcement. The exact level of stresses in these elements is not well known or at least there exists a lack of knowledge about their exact role.

The X-rays do not make distinction between residual stresses and stresses resulting from the applied loading. They detect the parameter that identifies the stresses state, that is to say the variation of the distance " $\mathrm{d}$ " between the crystallographic planes [7-12] of the material. The X-ray diffraction phenomenon is a "reflection" of an incident radiation over the crystallographic planes of material lattice, which only takes place for a particular angle of incidence $\left(\theta_{0}\right)$. Unlike the diffraction, reflection has place for all the inclinations of incident beams. The diffraction phenomenon must be understood under quantum mechanics science explanation far the objectives of this paper. The relationship between the separation of the crystallographic planes (defined by their Miller numbers " $h, k, l$ " with first order of diffraction) of a phase $\left(\mathrm{d}_{0}\right)$ and the inclination of diffraction $\left(\theta_{0}\right)$, is controlled by Bragg`s diffraction law $[4,5]$ :

$$
2 d_{0} \operatorname{sen} \theta_{0}=\lambda
$$

where $\lambda$ is the radiation wavelength. Stresses (residual or not) are manifested by a new value of the distance between the crystallographic planes " $\mathrm{d}_{\varphi \psi}$ " with regard to the value in the unloaded situation $\left(\mathrm{d}_{0}\right)$. This variation causes a variation of $\theta_{\varphi \psi}$ with regard to $\theta_{0}$ according Bragg's law. Differentiation of Bragg's law yields the relationship between the strain $\varepsilon_{\varphi \psi}$ of the deformed crystal and the angular shift of the diffraction beam $\left(\theta_{\varphi \psi}-\theta_{0}\right)$

$$
\varepsilon_{\varphi \psi}=\frac{\left(d_{\varphi \psi}-d_{0}\right)}{d_{0}}=-\cot g \theta_{0}\left(\theta_{\varphi \psi}-\theta_{0}\right)
$$

where $\varphi$ and $\psi$ are the angles (rotation and tilt) of the normal direction to the diffracting lattice planes in the fixed coordinate system, fig. 1. In addition, considering a continuous, homogeneous and isotropic material (general conditions in the steel components except in very specific cases in which the material presents a texture) and considering small stresses gradients in the volume affected by radiation (circle of $2 \mathrm{~mm}$ in diameter in surface and $0.1 \mathrm{~mm}$ depth) Hooke's law allows the deduction of the following expression:

$$
\varepsilon_{\varphi \psi}=\frac{1+v}{E} \sigma_{\varphi} \operatorname{sen}^{2} \psi-\frac{v}{E}\left(\sigma_{11}+\sigma_{22}\right)
$$


where

$$
\sigma_{\varphi}=\sigma_{11} \cos ^{2} \varphi+\sigma_{22} \operatorname{sen}^{2} \varphi
$$

Here $\sigma_{\varphi}$ represents the value of the stresses that support the material in the direction defined by $\varphi, \psi=\pi / 2$, fig. 1 , whereas $\sigma_{11}$ and $\sigma_{22}$ are the principal stresses. Obviously it has been considered a plane state of stresses in the vicinity of the sample surface $\left(\sigma_{i 3}=0\right)$. Eqn. (3) is the "sen ${ }^{2} \psi$ " law [4-10]. The slope of the $\varepsilon_{\varphi \psi}$ vs "sen ${ }^{2} \psi$ " function is directly related with the stresses on the surface of the material. Thus the X-ray diffraction equipment registers the values of $\varepsilon_{\varphi \psi}$ in each direction defined by the angles $\varphi, \psi$. The stress $\sigma_{\varphi}$ can be calculated if the values of the mechanical constants of the steel are known. In normal applications these values can be taken from the bibliography.

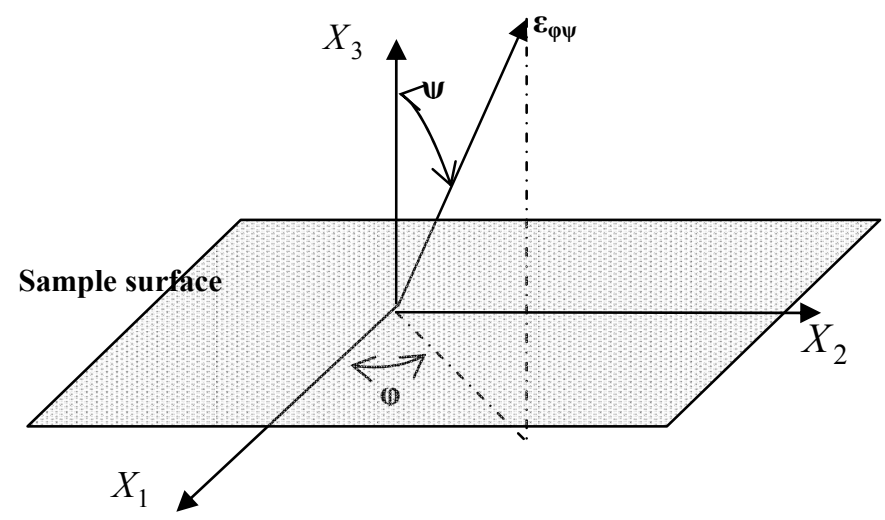

Figure 1: $\left\{\mathrm{X}_{\mathrm{i}}\right\}$ represents the principal stresses reference system whereas the direction of $\varepsilon_{\varphi \psi}$ is coincident with the normal to the diffracting planes.

\section{Experimental tests and results}

A small metallic structure (ferritic steel) has been built for the experimental laboratory tests, fig. 2. It is constituted by two simple structures connected by bolts. At the top and bottom two plates have been welded to receive the load from the compression machine whereas four metallic profiles assure the vertical displacement of the set when it is loaded. Inclined bars are $38 \mathrm{~cm}$ in length and section of $15 \times 40 \mathrm{~mm}^{2}$ whereas the horizontal bar is $70 \mathrm{~cm}$ in length and same section. The connection system between bars generates an inclination of $14^{\circ}$ for the inclined bars with respect the horizontal direction. The residual stresses have been quantified by X-ray diffraction technique before the load processes. After of this initial step the structure has been repeatedly loaded in a conventional 


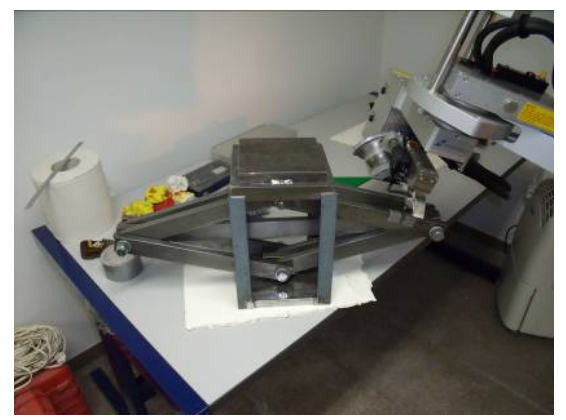

Figure 2: $\quad$ Sight of the tested structure.

compression machine. For each load process four known loads (near to 1000, 2000,3000 and $4000 \mathrm{Kp}$ ) over the structure have been applied. At each level of load the stresses in a point of one of the bars have been quantified by X-ray diffraction, figs. 3 and 4 , in order to compare them with the machine loads. In total it has been obtained 8 values of stresses by X-ray diffraction (two load processes and four loads for each process) giving the results shown in table 1 .

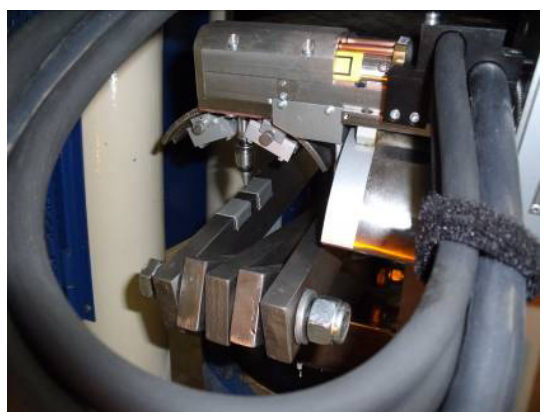

Figure 3: Detail of the measurement process.

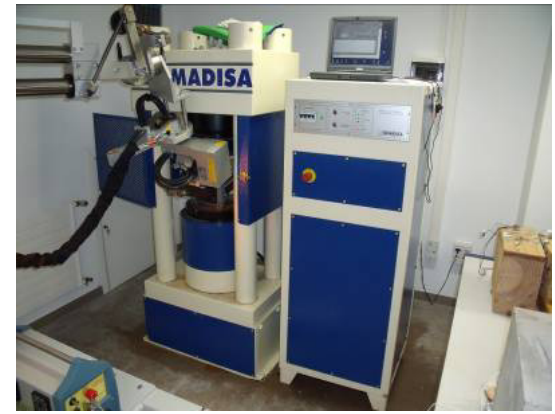

Figure 4: General sight of the measurement process. 
Table 1: $\quad$ Summary of the results obtained for all experimental tests.

\begin{tabular}{|c|c|c|c|c|}
\hline $\begin{array}{c}\text { External } \\
\text { load } \\
(\mathrm{Kp})\end{array}$ & $\begin{array}{c}\text { Nominal } \\
\text { value of } \\
\text { stresses } \\
(\mathrm{Mpa}) \text { in the } \\
\text { bar }\end{array}$ & $\begin{array}{c}\text { Stresses (Mpa) } \\
\text { obtained by } \\
\text { means of X-ray } \\
\text { diffraction }(\boldsymbol{\sigma})\end{array}$ & $\begin{array}{c}\text { Structural } \\
\text { stresses } \\
\left(\boldsymbol{\sigma}-\boldsymbol{\sigma}_{\mathbf{R}}\right) \\
(\mathrm{Mpa})\end{array}$ & $\begin{array}{c}\text { Differences } \\
\text { between } \\
\text { nominal loads } \\
\text { and X-ray } \\
\text { results }\end{array}$ \\
\hline 0 & 0 & $\begin{array}{c}25 \text { (residual } \\
\left.\text { stresses } \boldsymbol{\sigma}_{\mathbf{R}}\right)\end{array}$ & 0 & 0 \\
\hline 1000 & -17 & 0 & -25 & 8 \\
\hline 1100 & -19 & 2 & -23 & 4 \\
\hline 2000 & -35 & -16.7 & -41.7 & 8 \\
\hline 1950 & -34 & -17 & -42 & 1 \\
\hline 2900 & -51 & -27 & -52 & 2 \\
\hline 3100 & -54 & -27 & -52 & 4 \\
\hline 4050 & -71 & -50 & -75 & 3 \\
\hline 4250 & -75 & -53 & -78 & \\
\hline
\end{tabular}

\section{Brief discussion and conclusions}

The main problem for the experimental measurements with X-ray equipment is the positioning of the X-ray head with respect to the element analysed. The centre of the goniometer circumference has to be coincident with the material surface, fig. 5. Slight misalignment produces considerable variations of the stresses results. The equipment (standard STRESSTECH X-3000) disposes of three different configurations. For laboratory tests the configuration shown in fig. 6 allows the three spatial displacements and the three spatial rotations. For in-situ measurements there are two configurations depending of the fixing system of the X-ray head: either the goniometer is fixed to a tripod or attached to one magnetic arm, fig. 7.



Figure 5: Relative position between the goniometer and the structure. 


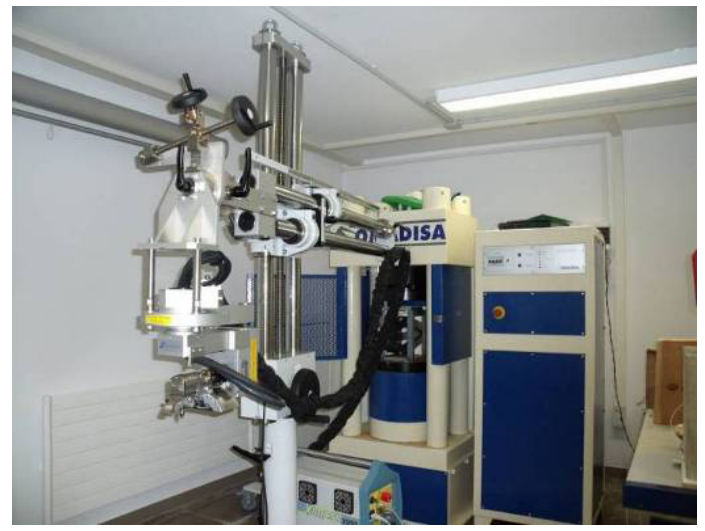

Figure 6: Laboratory configuration of the equipment.

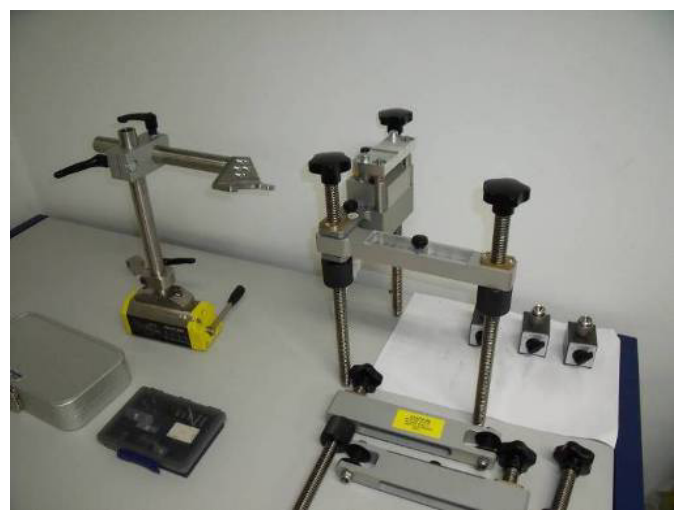

Figure 7: Mechanical devices for in situ configurations.

With respect to the steps of load it must be mentioned that the compression machine does not maintain exactly the load during the X-ray measurements (five minutes). A variation of $+/-100 \mathrm{Kp}$ is detected in all the cases. Considering the above comments the correlation between X-ray measurements and the applied loads in compression machine is excellent. Consequently the X-ray diffraction technique must be considered as non destructive procedure for stresses analysis in metallic structures.

\section{Acknowledgement}

The research has been financed by the Spanish Government (CDTI, Industry Ministry). 


\section{References}

[1] Proceedings of the ICRS 2 (Int. Conf. on Residual Stresses). Nancy (France), 1989

[2] Proceedings of the ICRS 3 (Int. Conf. on Residual Stresses). Tokushima (Japan) 1991

[3] Proceedings of the European Conf. on Residual Stresses 1 to 7

[4] Report N 22, ENSAM (Paris-France), 1981

[5] Residual stresses measurements by X-ray diffraction, ASTM SAETransactions., J784a, Society of Automotive Engineers, Inc., Second Edition, p. 1-119. 1971.

[6] S. Sánchez-Beitia, Calibration of the X-Ray Diffraction Technique for Stress Quantification in Metallic (Steel) Structures, Experimental Mechanics, Accepted: 6 December 2010

[7] F. Artaraz and S. Sánchez-Beitia. An unsuitable residual stresses state in train springs originated by shot peening. International Journal on Fatigue. Vol. 13 N 2, pp. 165-168. Imperial College Ed., London, 1991.

[8] F. Artaraz, A. Gil, A. Irisarri and S. Sánchez-Beitia. Residual Stresses generated in welded joints of SA CL1 steel. Proceedings of the IAEA (Int. Agency of Atomic Energy), Meeting of specialists of nuclear power plants. October 1989, Buenos Aires (Argentina)

[9] S. Sánchez-Beitia and M. Elices. Influencia de las tensiones residuales superficiales sobre la fragilización por hidrógeno en aceros eutectoides trefilados (in Spanish). Rev. Iberoamericana de Corrosión y Protección. Vol XVII (1), Enero 1986.

[10] V. Monine, J.R. Tendósio and T. Gurova. Study and service control of stress state of high strength steel cables used in prestressed concrete structures. International Centre for Diffraction Data, 2001, Advances in Xray Analysis, Vol. 44, pp. 195-200.

[11] S. Sánchez-Beitia Stresses quantification in structural steel bars by X-ray diffraction technique. PART I: Concepts. Proceedings of REHABEND 2009 Congress. October 2009, Bilbao (Spain).

[12] S. Sánchez Beitia, L. Ramos, P. Lourenço, J. Elices, I. Lombillo and L. Villegas. Stresses quantification in structural steel bars by X-ray diffraction technique. PART II: On site measurements. Proceedings of REHABEND 2009 Congress. October 2009, Bilbao (Spain). 